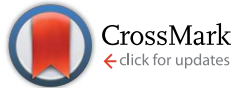

Cite this: RSC Adv., 2017, 7, 16737

www.rsc.org/advances

\section{Correction: An environmentally benign approach to achieving vectorial alignment and high microporosity in bacterial cellulose/chitosan scaffolds}

Guohui Li, ${ }^{a}$ Avinav G. Nandgaonkar, ${ }^{\text {ab }}$ Youssef Habibi, ${ }^{c}$ Wendy E. Krause, ${ }^{d}$ Qufu Wei ${ }^{\star a}$ and Lucian A. Lucia*abd

Correction for 'An environmentally benign approach to achieving vectorial alignment and high microporosity in bacterial cellulose/chitosan scaffolds' by Guohui Li et al., RSC Adv., 2017, 7, 13678-13688.

The authors regret that a funding body was not included in the Acknowledgements section of the original article. A revised version of the Acknowledgements section, in which funding from the China Scholarship Council is included below.

The Royal Society of Chemistry apologises for these errors and any consequent inconvenience to authors and readers.

\title{
Acknowledgements
}

The manuscript was written through contributions of all authors. All authors have given approval to the final version of the manuscript. These authors contributed equally. The authors thank Judy Elson for help in running the FE-SEM. We also thank the United Soybean Board (USB) and the State Scholarship Fund from China Scholarship Council for providing partial funding for this work and thank Jiangnan University for the Foreign Talent Professorship that allowed LAL to complete parts of this work.

${ }^{a}$ Key Laboratory of Eco-Textiles, Ministry of Education, Jiangnan University, 1800 Lihu Avenue, Jiangsu Province, Wuxi 214122, P. R. China. E-mail: lalucia@ncsu.edu ${ }^{b}$ Key Laboratory of Pulp and Paper Science \& Technology, College of Light Chemical \& Environmental Engineering, Qilu University of Technology, Jinan, 250353, P. R. China ${ }^{c}$ Department of Materials Research and Technology (MRT), Luxembourg Institute of Science and Technology (LIST), 5 Avenue des Hauts-Fourneaux, L-4362 Esch-sur-Alzette, Luxembourg

${ }^{d}$ Fiber and Polymer Science Program, North Carolina State University, 2401 Research Dr, Campus Box 8301, Raleigh, NC 27695-8301, USA 